\title{
Technical considerations to avoid pitfalls during transapical aortic valve implantation
}

\author{
Daniel R. Wong, MD, MPH, Jian Ye, MD, Anson Cheung, MD, John G. Webb, MD, \\ Ronald G. Carere, MD, and Samuel V. Lichtenstein, MD, PhD
}

\begin{abstract}
Objective: Transapical aortic valve implantation is a recent therapeutic advance for aortic valvular disease. We sought to identify complications - and the relevant technical and management considerations - from our learning curve with this procedure.
\end{abstract}

\begin{abstract}
Methods: We retrospectively reviewed perioperative complications during the first 60 transapical aortic valve implantations at a single institution, performed under compassionate release for patients who were candidates neither for conventional aortic valve replacement nor for transfemoral aortic valve implantation. Access was through a small left anterolateral thoracotomy. Particular attention was paid to securing the apical access site. Rapid ventricular pacing to reduce cardiac forward flow was used during balloon valvuloplasty and valve deployment. Careful positioning was guided by echocardiography and fluoroscopy.

Results: This was a select, high-risk (mean Society of Thoracic Surgeons score, $12.3 \% \pm 7.8 \%$ mortality) cohort. Mean age was $81.1 \pm 7.8$ years. Technical success was achieved in $59(98.3 \%)$ cases. One valve was malpositioned too far toward the ventricle, necessitating that a second device be implanted within it. In-hospital, 30-day mortality was $18.3 \%$ (11 deaths) overall, decreasing from $33.3 \%$ in the first 15 patients to $13.3 \%$ in the subsequent 45 patients. The only intraoperative death probably resulted from left main ostial obstruction by extensively calcified aortic cusps. Significant left ventricular apical bleeding occurred in $3(5.0 \%)$ patients. Other complications included stroke in $2(3.3 \%)$ patients and permanent atrioventricular block in $3(5.0 \%)$. There were $4(6.6 \%)$ cases of late pseudoaneurysm of the left ventricular apical access site.
\end{abstract}

Conclusions: Important lessons have been learned from our early experience with transapical aortic valve implantation, and these may guide others as this technology is adopted more broadly. (J Thorac Cardiovasc Surg 2010;140:196-202)

Since the first implant by Cribier and associates, ${ }^{1}$ transcatheter aortic valve implantation ushered in a new era in the surgical treatment of aortic stenosis. ${ }^{2}$ For high-risk patients with multiple comorbidities, this technique can provide relief of valvular stenosis, ${ }^{3}$ often with less morbidity than conventional aortic valve replacement (AVR).

To date, transfemoral and transapical transcatheter aortic valve implantation has only been offered in North America to very high-risk patients on a compassionate basis ${ }^{4-8}$ or in the context of a trial. Consequently, perioperative risks remain high by virtue of patients' comorbid conditions and poor preoperative medical status. Because such patient factors are immutable, mitigating the procedural risks through good surgical technique becomes pivotal in tipping the balance of outcome from risk to benefit.

From the Divisions of Cardiac Surgery and Cardiology, St Paul's Hospital, University of British Columbia, Vancouver, British Columbia, Canada.

Disclosures: Anson Cheung and John Webb report fees and grant support from Edwards.

Received for publication March 30, 2009; revisions received July 2, 2009; accepted for publication July 23, 2009; available ahead of print Feb 1, 2010.

Address for reprints: Jian Ye, MD, Division of Cardiac Surgery, St. Paul's Hospital, 1081 Burrard St, Vancouver, BC, Canada V6Z1Y6 (E-mail: jye@providencehealth.bc.ca). $0022-5223 / \$ 36.00$

Copyright (c) 2010 by The American Association for Thoracic Surgery doi:10.1016/j.jtcvs.2009.07.081
$\mathrm{We}^{9}$ have been performing transapical aortic valve implantation (TAVI) since October 2005. As the technology moves toward widespread availability, operators and patients will benefit from the experience gained to optimize the learning curves of new implanting centers. Whereas step-by-step descriptions of the implantation procedure have been outlined previously, ${ }^{10}$ our objective was to focus specifically on key techniques for avoiding important complications.

\section{METHODS \\ Patient Population}

TAVI was performed on a compassionate basis in 60 patients who were declined for conventional AVR and not suitable for a transfemoral approach. Patients were elderly (mean age, $81.1 \pm 7.8$ years), with multiple comorbid conditions and a high predicted mortality for AVR (mean Society of Thoracic Surgeons score, $12.3 \% \pm 7.8 \%$, logistic EuroScore $35.1 \% \pm$ $20.3 \%)$.

\section{Surgical Technique}

The TAVI procedure has been previously described. ${ }^{8,10}$ In our center, TAVI was performed in a surgical suite, with fluoroscopy-initially using a C-arm until a hybrid suite was constructed-and transesophageal echocardiography (TEE). ${ }^{11}$ A 4- to 5-cm anterolateral minithoracotomy incision was centered over the apex of the left ventricle (LV) in the fifth or sixth intercostal space, and the pericardium was opened. Apical sutures were inserted to secure the access site. By needle puncture and standard 


\section{Abbreviations and Acronyms \\ $\mathrm{AVR}=$ aortic valve replacement \\ $\mathrm{LV}=$ left ventricle (ventricular) \\ TAVI $=$ transapical aortic valve implantation \\ TEE $=$ transesophageal echocardiography}

over-the-wire techniques, the LV apex was accessed with a $7 \mathrm{~F}$ sheath and the aortic valve crossed with a 0.035-inch Amplatz Extra Stiff wire (Boston Scientific Corp, Natick, Mass). A 100-cm pigtail catheter was introduced via the femoral artery. Systemic heparin was administered to achieve an activated clotting time of more than 300 seconds. Balloon aortic valvuloplasty was performed through a $14 \mathrm{~F}$ sheath with a $20-\mathrm{mm} \times 5-\mathrm{cm}$ (or 3-cm) noncompliant, high-pressure Z-MED balloon (NuMED, Inc, Hopkinton, NY) during rapid ventricular pacing with temporary epicardial wires. ${ }^{12}$ The Edwards SAPIEN transcatheter valve (Edwards LifeSciences, LLC, Irvine, Calif) is constructed of a bovine pericardial trileaflet valve within a stainless steel stent and is available in 23- and 26-mm diameter sizes. The valve was crimped on the delivery balloon, introduced via a $33 \mathrm{~F}$, or more recently a $26 \mathrm{~F}$, sheath, and, once in position, balloon-deployed during rapid pacing. Valve function and position were assessed by TEE and completion aortography. The LV apical sutures were tied to secure hemostasis. The incision was closed in layers and a chest tube was inserted.

\section{Analysis of Outcomes}

Preoperative characteristics and short-term complications were recorded prospectively in an institutional transcatheter valve database; additional details regarding complications were extracted by retrospective chart review. Ethics approval for this research was granted with waiver of individual consent. Continuous variables were reported as means \pm standard deviation and discrete variables as number (percent) unless otherwise specified.

\section{RESULTS}

Technical success was achieved in 59 (98.3\%) patients. One valve was malpositioned too far toward the ventricle, and we successfully deployed a second transcatheter valve slightly cephalad inside the first. Overall 30-day mortality was $18.3 \%$ (11 deaths), including 1 patient (from among our first 15 cases) who died intraoperatively, likely of left main occlusion by a heavily calcified native cusp. In-hospital 30-day mortality was $33.3 \%$ in the initial 15 patients, decreasing to $13.3 \%$ in the final 45 patients.

Short-term complications during the postoperative course were often related to patient comorbid conditions. Intraoperative bleeding occurred in $5(8.3 \%)$ patients, with $3(5.0 \%)$ cases of LV apical hemorrhage extending through friable LV free wall tissue necessitating femoral-femoral bypass, sternotomy without bypass, or extensive off-pump repair with pledget-supported sutures. Three patients had postoperative bleeding complications, including gastrointestinal and thoracic wall variceal bleeding. Other complications included multiple microembolic strokes in $2(3.3 \%)$ patients: 1 patient with concomitant hypoxic-ischemic encephalopathy did not awaken postoperatively, and 1 patient had left arm hemiparesis. There was 1 case each
$(1.7 \%)$ of ischemic bowel, ischemic leg, and multiorgan dysfunction, and there were 2 cases each $(3.3 \%)$ of wound infection and fatal pulmonary embolism. Incident atrioventricular node block necessitating a permanent pacemaker occurred in $3(5.0 \%)$ patients, including the 1 patient with device malposition. One patient had late (day 55) ventricular migration of the valve, and AVR for significant transvalvular and paravalvular regurgitation 119 days after implantation was complicated by a fatal postoperative stroke.

Four $(6.6 \%)$ cases of LV apical pseudoaneurysm at the access site were identified. One frail patient had apical hemorrhage intraoperatively and died while awaiting repair; another required immediate anticoagulation for recurrent vascular graft thromboses, putatively facilitating oozing from friable apical myocardium, and underwent repair 7 months later. Conservative management and observation was carried out for the other 2 pseudoaneurysms, both of which were associated with deep wound infections, and 1 thrombosed spontaneously.

\section{DISCUSSION}

The adoption of new technology for a high-risk population can be extremely challenging, and patient selection is key. Unfortunately, predictive scores for AVR often underestimate risk because they are derived from surgical candidates and do not consider frailty, prolonged preoperative hospitalization, immobility, extreme deconditioning, porcelain aorta, liver failure, incomplete coronary revascularization, or other uncorrected valvular disease. These factors likely explain the discrepancy between the observed $(17.6 \%)$ and predicted mortality (Society of Thoracic Surgeons score for standard AVR, 12.4\% \pm $7.5 \%$; logistic EuroSCORE $35 \% \pm 20 \%$ ). The Leipzig group has reported results similar to ours, with $92 \%$ 1-month survival among their first 50 patients, although this includes $16(32 \%)$ on-pump implants; we did not perform any of our implants with pump support, and there may be other differences between patient populations. ${ }^{13}$

Precisely because of the excessive risks associated with these patients' fixed preoperative characteristics, we believe that procedural technique is vitally important as one potentially modifiable factor. Lessons learned from our experience-as detailed in the following discussion and illustrations and summarized in Table 1-may assist others to identify and avoid pitfalls during TAVI and reduce adverse outcomes.

\section{Room and Setup}

A suitable room must be large enough to accommodate all personnel, equipment, and a sterile back table. Sufficient slack on the ventilator and intravenous tubing will permit easier patient repositioning on the floating top, radiolucent table; and a hybrid operating room with a ceiling-mounted image intensifier and multiple monitors is preferable to 
TABLE 1. Complications and pitfalls during transcapical aortic valve implantation, with frequency of occurrence and methods to avoid and manage them

\begin{tabular}{|c|c|c|}
\hline Complication/pitfall & Frequency, n (\%) & Avoidance maneuver and management \\
\hline $\begin{array}{l}\text { Suboptimal intercostal space } \\
\text { (difficulty placing apical sutures and } \\
\text { directing sheaths) }\end{array}$ & - & $\begin{array}{l}\text { - Widely drape patient } \\
\text { - Elevate left chest with roll under patient } \\
\text { - Localize apex on surface with hemostat by fluoroscopy } \\
\text { - Confirm selection of intercostal space over apex } \\
\text { visually } \\
\text { - Select lower intercostal space of two otherwise equal } \\
\text { spaces }\end{array}$ \\
\hline $\begin{array}{l}\text { Poor visibility of LV apex (difficulty } \\
\text { placing apical sutures) }\end{array}$ & - & $\begin{array}{l}\text { - Select nearest intercostal space (see above) } \\
\text { - Enlarge incision } \\
\text { - Excise excess pericardial adipose tissue } \\
\text { - Suspend pericardial cut edges }\end{array}$ \\
\hline LV apical hemorrhage & $3(5.0 \%)$ & $\begin{array}{l}\text { - Avoid epicardial fat and friable tissue } \\
\text { - Access true LV apex, not free wall, if possible } \\
\text { - Ensure deep (full-thickness, if possible) myocardial } \\
\text { bites with control sutures: use large needles } \\
\text { - Use pledgets to buttress control sutures } \\
\text { - Circumscribe apex widely with control sutures (larger } \\
\text { area than largest sheath to be used) } \\
\text { - Center needle puncture within control sutures } \\
\text { - Avoid excessive movement/angulation of sheaths } \\
\text { - Reinforce apex with extra pledget-supported sutures as } \\
\text { required } \\
\text { - Do not incorporate pericardium into the closure to } \\
\text { avoid obscuring bleeding } \\
\text { - Use cardiopulmonary bypass to repair severe bleeding } \\
\text { (consider rapid ventricular pacing) }\end{array}$ \\
\hline Hemorrhage & $5(8.3 \%)$ & $\begin{array}{l}\text { - Ensure hemostasis of chest wall, including chest tube } \\
\text { sites } \\
\text { - Place epicardial pacing sutures where easily visible } \\
\text { - Avoid LV apical hemorrhage (see above) }\end{array}$ \\
\hline LV apical pseudoaneurysm & $4(6.6 \%)$ & $\begin{array}{l}\text { - Maintain sterile technique } \\
\text { - Avoid LV apical hemorrhage (see above) } \\
\text { - Avoid early anticoagulation if possible } \\
\text { - Manage wound infections and hypertension } \\
\text { - Sugressively } \\
\text { - Surveil and, if possible, repair pseudoaneurysms }\end{array}$ \\
\hline Ineffective rapid ventricular pacing & - & $\begin{array}{l}\text { - Place epicardial pacing wires in visible myocardium } \\
\text { - Secure pacing wires (clip ends together, and tape pacing } \\
\text { wires to drapes) } \\
\text { - Test pacing and adjust settings to minimize pulsatile } \\
\text { flow } \\
\text { - Consider transvenous pacing as needed } \\
\text { - Ensure clear, two-way communication with operator }\end{array}$ \\
\hline Arrhythmia after rapid ventricular pacing & $1(1.7 \%)$ & $\begin{array}{l}\text { - Place and connect defibrillator pads for all cases } \\
\text { - Limit pacing to minimum required }\end{array}$ \\
\hline Balloon slippage during valvuloplasty & - & $\begin{array}{l}\text { - Use } 5-\mathrm{cm} \text { length balloon } \\
\text { - Ensure sheath not interfering with balloon (visualize } \\
\text { sheath by filling with contrast and pull back as needed) } \\
\text { - Only inflate balloon during effective rapid ventricular } \\
\text { pacing (and deflate before cessation of pacing) }\end{array}$ \\
\hline
\end{tabular}


TABLE 1. Continued

\begin{tabular}{|c|c|c|}
\hline Complication/pitfall & Frequency, n (\%) & Avoidance maneuver and management \\
\hline Valve malpositioning & $1(1.7 \%)$ & $\begin{array}{l}\text { - Do not rush positioning } \\
\text { - Identify aortic annulus, cusps, and sinuses using TEE, } \\
\text { fluoroscopy } \pm \text { contrast, and pigtail catheter position } \\
\text { - Ensure coaxial alignment } \\
\text { - Perform balloon valvuloplasty first (easier to cross } \\
\text { calcified valve and adjust delivery device) } \\
\text { - Rapid ventricular pace if needed during positioning and } \\
\text { to avoid balloon slippage (see above) } \\
\text { - Consider valve-in-valve implant if malpositioned }\end{array}$ \\
\hline Coronary obstruction by native cusp & $1(1.7 \%)$ & $\begin{array}{l}\text { - Assess degree of cuspal calcifcation by TEE, especially } \\
\text { if eccentric, severe, and left cuspal } \\
\text { - Locate coronary ostia with aortography } \\
\text { - Assess degree of coronary obstruction during balloon } \\
\text { valvuloplasty } \\
\text { - Possibly consider placing coronary guidewire in ostium } \\
\text { if high risk for obstruction } \\
\text { - May require cardiopulmonary bypass to stabilize }\end{array}$ \\
\hline Valve embolization & 0 & $\begin{array}{l}\text { - Accurately size the annulus } \\
\text { - Oversize valve slightly, especially in absence of severe } \\
\text { calcification } \\
\text { - Ensure correct valve positioning (see above) }\end{array}$ \\
\hline Valve misorientation (upside-down) & 0 & $\begin{array}{l}\text { - Double check orientation ex vivo (green suture) and in } \\
\text { vivo (radiodense cranial half) before deployment }\end{array}$ \\
\hline $\begin{array}{l}\text { Excessive postoperative pain } \\
\quad \text { (respiratory compromise) }\end{array}$ & - & $\begin{array}{l}\text { - Avoid rib retraction; use soft tissue retractor } \\
\text { - Avoid unnecessarily large thoracotomy incision } \\
\text { - Infiltrate incision with local anesthetic agent } \pm \text { rib } \\
\text { blocks } \\
\text { - Use small chest tube }\end{array}$ \\
\hline
\end{tabular}

$L V$, Left ventricular; $T E E$, transesophageal echocardiography.

portable C-arm fluoroscopy with reduced image quality (Figure 1). A primed bypass circuit and instuments for peripheral and central cannulation must be readily available.

Double-lumen endotracheal intubation was unnecessary. The patient was widely draped and positioned supine with slight elevation of the left hemithorax. Electrocardiographic leads and defibrillator pads were placed out of the line of fluoroscopic sight; defibrillation was required after rapid pacing in 1 case.

\section{Incision}

Palpitation of the apex impulse for marking the optimal incision was often inaccurate in large patients with barrel chests. We now locate the apex fluoroscopically with a hemostat on the skin and commence with a small incision over a rib; this provided two intercostal spaces for consideration, with visual confirmation of proximity to the apex as the final arbitrator. Of two equally suitable intercostal spaces, the more inferior one generally allowed easier cranial angulation of the sheaths toward the aortic valve.
A soft tissue retractor (such as a radiolucent medium Alexis retractor [Applied Medical Resources Corp, Rancho Santa Margarita, Calif]) does not spread the ribs, thus minimizing postoperative pain, which is particularly important for patients with severe respiratory disease. Local bupivicaine and a small chest tube further reduce postoperative pain. Pericostal sutures are unnecessary.

Excess extrapericardial fat may be excised. Suspending the cut pericardial edges with heavy sutures often draws the apex closer for easier access.

\section{Apical Access}

Hemostatic control of the LV apex is the most critical and difficult step in TAVI owing to the large sheath and thin, friable tissue in this patient group. When placing apical control sutures, avoid epicardial fat, which provides no additional strength, and take deep bites in the myocardium, preferably full-thickness bites (Figure 2, $A$ ). The true apex is preferable to the free wall for minimizing myocardial tearing (owing to lower tension from greater convexity, per 
LaPlace's law), although occasionally apical fat or a large left anterior descending or diagonal coronary artery necessitated choosing a slightly more lateral site.

We used 3-0 polypropylene sutures on a big MH (medium half [circle] $)$ needle with large $(1 \times 2 \mathrm{~cm})$ felt pledgets to make 2 perpendicular horizontal mattress sutures to control the LV apex and snared them through tensioning tourniquets. The area bounded by these apical sutures should be approximately $1.5 \mathrm{~cm}$ in diameter and larger than the largest delivery sheath (currently $26 \mathrm{~F}$, although we also previously used $33 \mathrm{~F}$ sheaths). Other methods, such as a purse-string technique, have also been used by other groups, ${ }^{14}$ but may require a larger skin incision and more rib spreading to place the sutures.

Next, it is important to make the needle puncture precisely centrally within the sutures (Figure $2, B$ ). This reduces the likelihood of tearing the enlarging myocardial defect beyond the control sutures as larger sheaths are introduced stepwise.

Apical bleeding remains the Achilles' heel of the procedure. Bleeding usually can be contained with additional wide pledget-supported sutures, being sure to avoid torquing the needles when passing them through the beating heart. Sternotomy or on-pump repair may rarely be required to repair extensive tearing and bleeding, and rapid pacing or other maneuvers to reduce cardiac motion may also be considered. Do not incorporate the pericardial edges into the closure to stop bleeding, because this obscures the source of bleeding, with the exception being reoperations with dense pericardial adhesions. There may be value in additional apical sutures to also prevent pseudoaneurysm formation, especially if early postoperative anticoagulation is necessary.

\section{Valvuloplasty}

Two temporary epicardial ventricular pacing wires should be placed where bleeding would be easy to identify, inasmuch as removal occasionally caused bleeding and in 1 case local tamponade. The wires are clipped together with a surgical clip (Figure 2, $B$ ) and taped to the drapes to prevent accidental dislodgment. We first tested pacing (1-V output) at a rate just greater than intrinsic, then at 160 to 200 beats/min, with $20-\mathrm{V}$ output. If 2:1 block occurs with rapid pacing, the pacing rate is reduced. The duration of rapid ventricular pacing should be minimized, particularly in patients with poor LV function or significant coronary artery disease. Rapid pacing should not be reinstituted before full hemodynamic recovery. Transvenous pacing was rarely required.

Preimplant aortic valvuloplasty (Figure 3) not only makes deployment easier but also facilitates passing the device across the native valve and enlarges the orifice to permit flow during implant positioning. Furthermore, it may help to assess the potential for coronary ostial obstruction owing to heavily calcified native cusps, and it is therapeutic in and of itself for relieving aortic stenosis, albeit temporarily, if TAVI must be aborted.

Balloon slippage during valvuloplasty, with the need for repeat dilation, has been largely eliminated with the antegrade approach and a longer $(5-\mathrm{cm})$ balloon; a $3-\mathrm{cm}$ balloon is used in patients with prior mitral valve replacement. The radiolucent $14 \mathrm{~F}$ sheath can be visualized if filled with contrast and should be pulled back to avoid interfering with balloon inflation.

\section{Valve Sizing, Positioning, and Deployment}

Accurate sizing of the aortic annulus is most reliably performed with intraoperative TEE, by measuring between the aortic cusp hinge points in a long-axis view (Figure 4). Generally speaking, computed tomography gives a larger annular measurement than TEE, and transthoracic echocardiography measures smaller. A 26-mm valve is selected for a $22-$ to $25-\mathrm{mm}$ annulus but may be used in a $26-\mathrm{mm}$ annulus if significantly calcified; a 23-mm valve is used for a 17- to 21-mm annulus. Correct orientation of the valve on the delivery system must be checked: the green suture is oriented to the inflow (ventricular) side, and the distal (cephalad) half of the
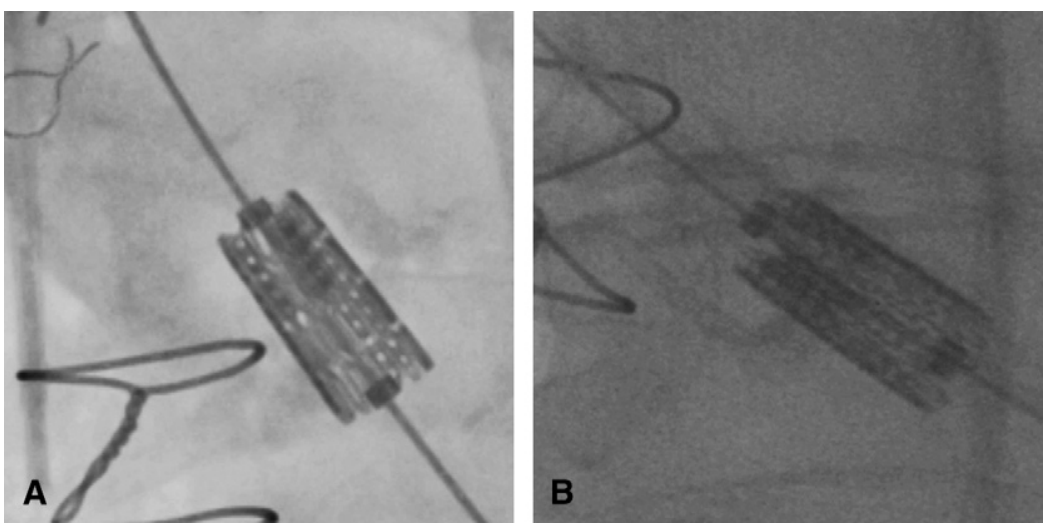

FIGURE 1. Comparison of high-quality fluoroscopic images of the transcatheter valve obtained from hybrid room image intensifier (A) versus standard C-arm fluoroscopy (B). The ascending aorta is at the top left corner, and the left ventricular apex is beyond the bottom right corner. 

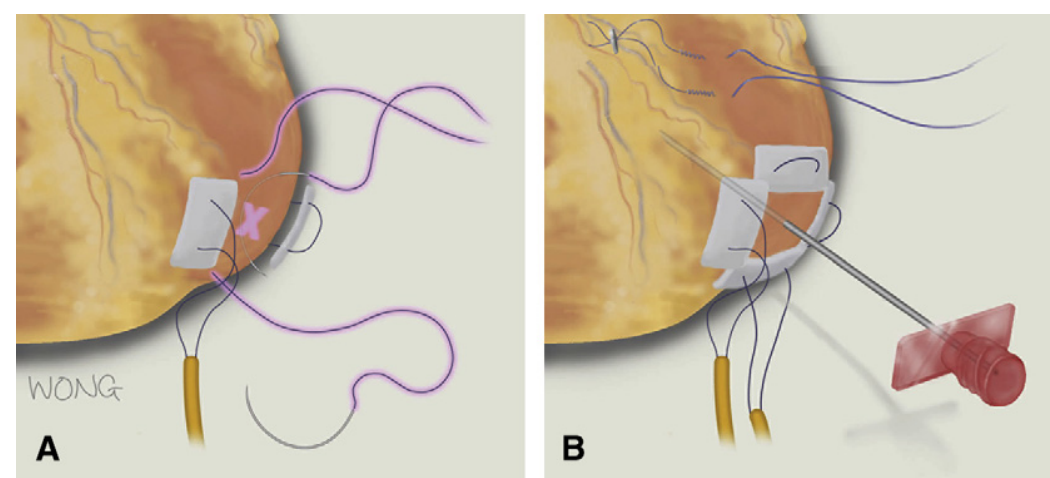

FIGURE 2. Technique for hemostatic control of the left ventricular apex. A, Two perpendicular, pledget-supported sutures are placed at the apex $(X)$ to avoid epicardial fat and vessels; the suture (highlighted) is passed full-thickness through myocardium and then snared with a tensioning tourniquet. B, A needle is passed through the apex at the central point bounded by the pledget-supported sutures. Temporary ventricular pacing wires are also shown.

crimped valve appears slightly more radiodense by fluoroscopy (Figure 1) before deployment. By confirming the orientation with two operators, we have never had any valves implanted upside-down.

The valve is positioned such that $40 \%$ to $50 \%$ of the stent lies on the ventricular side of the calcified valve/annulus before deployment, and the distal edge of the deployed valve sits just cephalad to the free edge of the aortic cusps (Figures 1 and 5). Although we are usually more concerned about the distal end, placement too far toward the ventricle may also be problematic, because mitral valve perforation ${ }^{15}$ or valve embolization may occur with extreme positioning.

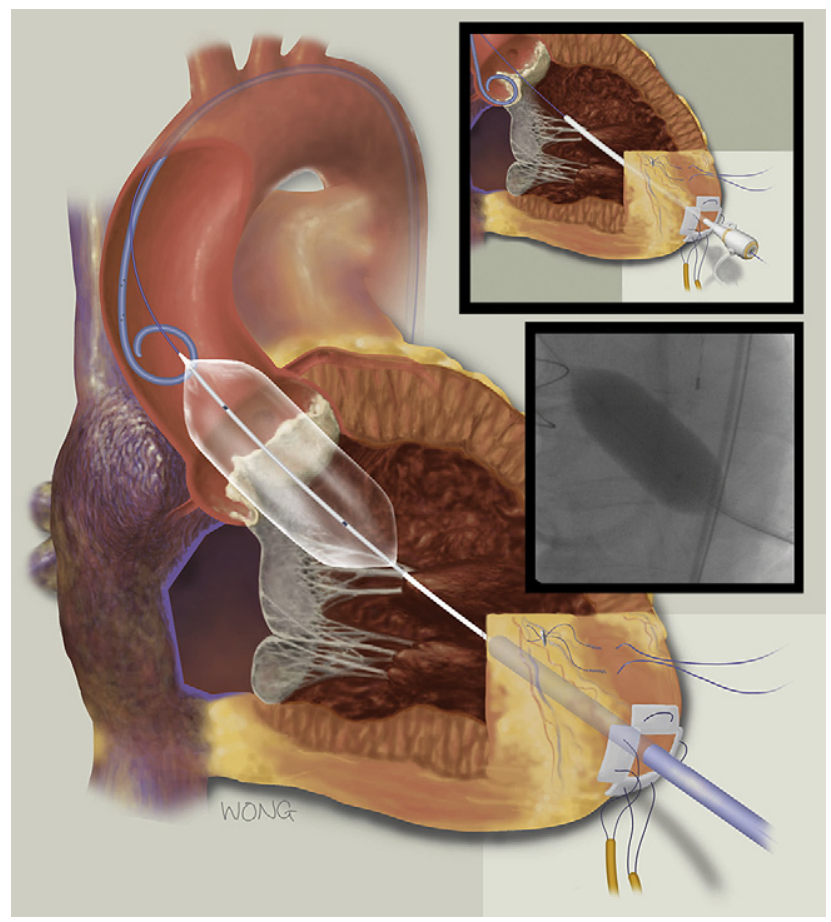

FIGURE 3. After the stenotic native aortic valve is crossed with a wire (top inset), balloon aortic valvuloplasty is performed during rapid ventricular pacing. Dilute contrast solution permits visualization of the balloon under fluoroscopy (bottom inset).
Obtaining proper coaxial alignment of the valve and aorta is easier with the transapical than retrograde transfemoral approach, particularly when there is any amount of horizontal angulation of the aortic root. This is best ensured by keeping the image intensifier perpendicular to the annular plane, although usually a straight anteroposterior angle will suffice. Beware of subtle axial misalignment of the crimped valve that becomes magnified after deployment.

Where there is little to no aortic calcification, the annulus can be located by TEE (Figure 5, top inset), root aortography with hand injections (Figure 5, bottom inset), and by positioning the radiopaque pigtail catheter to mark the lowest point of the cusps (Figure 1, $B$; the pigtail must pulled back before deployment to avoid entrapment with the transcatheter valve). The valve rarely needs to be deployed hurriedly; it is

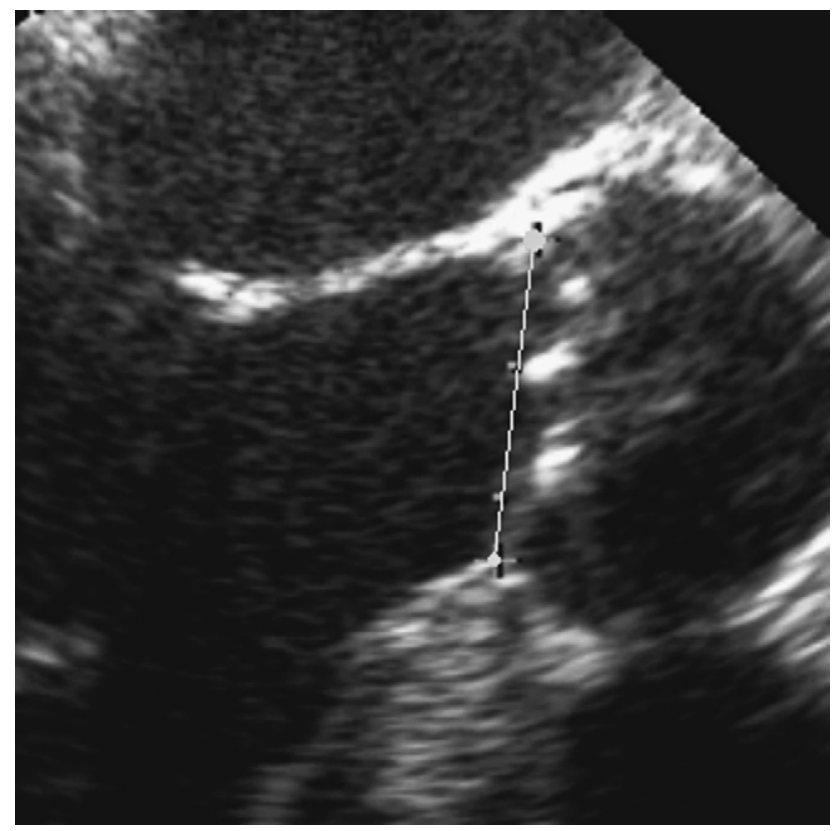

FIGURE 4. The aortic annulus is measured between hinge points to size the transcatheter valve, and transesophageal echocardiography is the most accurate means of measurement. 


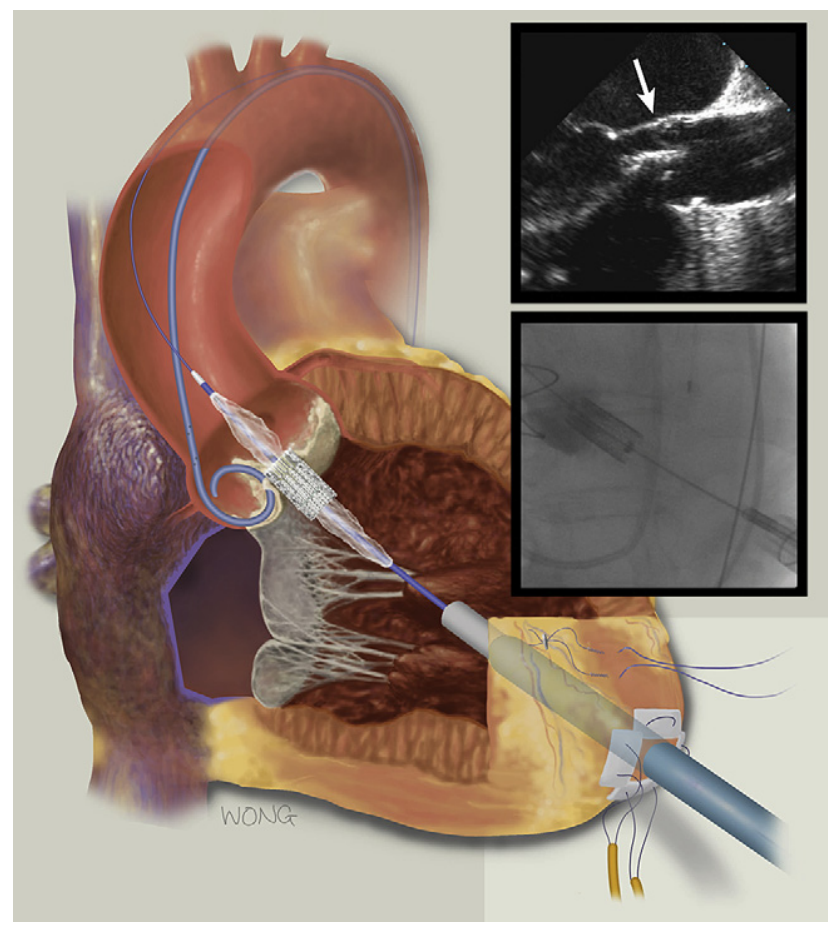

FIGURE 5. The transcatheter valve is positioned with transesophageal echocardiographic (top inset) and fluoroscopic guidance (bottom inset), with fine positioning adjustments informed by hand injections of contrast through a pigtail catheter deep in the aortic root. The valve is positioned so that $40 \%$ to $50 \%$ of the stent lies below the annulus (arrow) and so that the valve extends just cranial to the native cusp edges.

therefore prudent to position the valve meticulously. In rare cases, temporary rapid ventricular pacing will be needed to reduce excessive cardiac and annular motion during positioning.

\section{Postoperative Management}

Owing to the risk of falls and hemorrhagic complications early in our series, postoperative warfarin was abandoned in favor of aspirin $81 \mathrm{mg}$ plus clopidogrel $75 \mathrm{mg}$ once daily. Avoiding nephrotoxic drugs and limiting intravenous contrast are important, because renal insufficiency was common. Good hypertensive control may reduce the risk bleeding and apical pseudoaneurysms.

\section{CONCLUSION}

TAVI is a complementary technique to the transfemoral approach and offers several potential advantages, including greater stability during device delivery, avoidance of peripheral vascular access concerns, and reduced aortic arch instrumentation. Nevertheless, important technical challenges and the steep learning curve have implications for training and maintenance of competence.

\section{References}

1. Cribier A, Eltchaninoff H, Bash A, Borenstein N, Tron C, Bauer F, et al. Percutaneous transcatheter implantation of an aortic valve prosthesis for calcific aortic stenosis: first human case description. Circulation. 2002;106:3006-8.

2. Webb JG. Percutaneous aortic valve replacement will become a common treatment for aortic valve disease. J Am Coll Cardiol Intv. 2008;1:122-6.

3. Ye J, Cheung A, Lichtenstein SV, Altwegg LA, Wong DR, Carere RG, et al. Transapical transcatheter aortic valve implantation: 1-year outcome in 26 patients. J Thorac Cardiovasc Surg. 2009;137:167-73.

4. Webb JG, Chandavimol M, Thompson CR, Ricci DR, Carere RG, Munt BI, et al. Percutaneous aortic valve implantation retrograde from the femoral artery. Circulation. 2006;113:842-50.

5. Ye J, Cheung A, Lichtenstein SV, Pasupati S, Carere RG, Thompson CR, et al. Six-month outcome of transapical transcatheter aortic valve implantation in the initial seven patients. Eur J Cardiothorac Surg. 2007;31:16-21.

6. Webb JG, Pasupati S, Humphries K, Thompson C, Altwegg L, Moss R, et al. Percutaneous transarterial aortic valve replacement in selected high-risk patients with aortic stenosis. Circulation. 2007;116:755-63.

7. Walther T, Simon P, Dewey T, Wimmer-Greinecker G, Falk V, Kasimir MT, et al. Transapical minimally invasive aortic valve implantation: multicenter experience. Circulation. 2007;(11 Suppl):I240-5.

8. Lichtenstein SV, Cheung A, Ye J, Thompson CR, Carere RG, Pasupati S, et al. Transapical transcatheter aortic valve implantation in humans: initial clinical experience. Circulation. 2006;114:591-6.

9. Ye J, Cheung A, Lichtenstein SV, Carere RG, Thompson CR, Pasupati S, et al. Transapical aortic valve implantation in humans. J Thorac Cardiovasc Surg. 2006;131:1194-6.

10. Walther T, Dewey T, Borger MA, Kempfert J, Linke A, Becht R, et al. Transapical aortic valve implantation: step by step. Ann Thorac Surg. 2009;87:276-83.

11. Moss RR, Ivens E, Pasupati S, Humphries K, Thompson CR, Munt B, et al. Role of echocardiography and percutaneous aortic valve implantation. J Am Coll Cardiol Img. 2008;1:15-24.

12. Webb JG, Pasupati S, Achtem L, Thompson CR. Rapid pacing to facilitate transcatheter prosthetic heart valve implantation. Catheter Cardiovasc Interv. 2006;68:199-204.

13. Walther T, Falk V, Kempfert J, Borger MA, Fassl J, Chu MW, et al. Transapical minimally invasive aortic valve implantation: the initial 50 patients. Eur $J$ Cardiothorac Surg. 2008;33:983-8.

14. Walther T, Falk V, Borger MA, Dewey T, Wimmer-Greinecker G, Schuler G, et al. Minimally invasive transapical beating heart aortic valve implantationproof of concept. Eur J Cardiothorac Surg. 2007;31:9-15.

15. Wong DR, Boone RH, Thompson CR, Allard MF, Altwegg L, Carere RG, et al. Mitral valve injury late after transcatheter aortic valve implantation. J Thorac Cardiovasc Surg. 2009; 137:1547-9. 